\title{
Ultra structural Studies of Mouse Liver in Castrated Subjects Treated with Grape Juice
}

\author{
Homady M. H ${ }^{1 *}$, ALquraishi, L ${ }^{2}$, Ubeid, M. H $^{3}$, Juma, A. S. M $^{1}$ \\ ${ }^{1}$ College of Science, Department of Biomedical Sciences, Cihan University-Erbil, Kurdistan Region, Iraq. \\ ${ }^{2}$ College of Dentistry, Babylon University, Iraq. \\ ${ }^{3}$ College of Science, Department of General Biology, Cihan University-Erbil, Kurdistan Region, Iraq. \\ *Corresponding author: Homady, M. H, College of Science, Department of Biomedical Sciences, Cihan University-Erbil, Kurdistan Region, \\ Iraq. \\ Received date: December 07, 2020; Accepted date: January 25, 2021; Published date: January 27,2021 \\ Citation: Homady M. H, ALquraishi, L, Ubeid, M. H, Juma, A. S. M. (2021) Ultra structural Studies of Mouse Liver in Castrated Subjects Treated \\ with Grape Juice. International Journal of Clinical Case Reports and Reviews. 6(3); DOI: 10.31579/2690-4861/082 \\ Copyright: () 2021 Homady, M. H, This is an open-access article distributed under the terms of the Creative Commons Attribution License, which \\ permits unrestricted use, distribution, and reproduction in any medium, provided the original author and source are credited.
}

\begin{abstract}
The present study was designed to evaluate the alterations in the liver tissues especially ITO and Kupffer cells of both castrated and castrated mice treated with $10 \mu \mathrm{l} / \mathrm{g}$ of grape juice. The present study was conducted on forty five healthy males of Swiss albino mice, which were divided into 3 groups ( $\mathrm{N}=15$ mice per each group). The first group was intact (control); the second one was castrated and the third group was castrated treated with $10 \mu \mathrm{l} / \mathrm{g}$ of grape juice. The ultra-structure sections of liver tissue from intact (control) group showed normal structure of both hepatocytes and sinusoids, with smooth external surfaces. Whereas ultra-sections from castrated group resulted in: degeneration of hepatocytes, deterioration of sinusoids; rough external surfaces, with aggregations of lipid droplets and white blood cells as compared with the control group. However treatment of castrated subject's with $10 \mu \mathrm{l} / \mathrm{g}$ of grape juice resulted in activation the regeneration processes in both hepatocytes and sinusoids, with smooth appearance of the external surfaces as compared with control group.
\end{abstract}

The present study concluded that surgical castration aggravated increased hepatic steatosis and increased inflammatory response by increased activation of Kupffer and Ito cells, these effects could be reserved by aggravated increased grape juice administration.

Key words: liver; castration; grape juice; kupffer cells; scanning electron microscope

\section{Introduction:}

The mammalian liver is the largest internal digestive organ, which is indispensable in many essential physiologic processes and vulnerable to be impaired by a wide variety of factors, such as toxins, microorganisms, metabolic products, circulatory materials and metabolism of carbohydrates, lipids and proteins. [1, 2, 3].

Nonalcoholic fatty liver disease (NAFLD) is the most common chronic liver disease in the world. It is present in $30 \%$ of the general adult population. In reality, NAFLD comprise as a spectrum of hepatic abnormalities that are observable in liver histological slides, from a simple intrahepatic accumulation of fat (steatosis or nonalcoholic fatty liver, NAFL) to various degrees of necrotic inflammation (NASH nonalcoholic steatohepatitis, NASH) [ 4, 5, 6]. Kupffer cells, the hepatic resident macrophages, represent the largest group of macrophages in the body and account for about $20-25 \%$ of non-parenchymal cells in the liver (intrasinusoidal cells) [7, 8] . As the critical component of the innate immune system, Kupffer cells can be activated by various endogenous and exogenous stimuli, and play a key role in regulating the phenotype and function of neighboring parenchymal and non-parenchymal cells [9]. Hepatic stellate cells (HSCs) also called Ito cells, fat-storing cells, lipocytes, perisinusoidal cells and vitamin A-storing cells located in the space of Disse between hepatocytes and sinusoidal endothelial cells. These cells constitute approximately $10 \%$ of the total number of liver cells [10, 11, 12 and 13], and their cytoplasm is especially rich in lipid droplets and show long branched cytoplasmic processes that may reduce the lumen of sinusoid capillaries, in such a way modulating the liver sinusoidal blood flow. When the liver is damaged, the hepatic stellate cells change their shape and transform via a process named "activation" into the myofibroblast [14, 15 and 16]. All stages of NAFLD including cirrhosis and hepatocellular carcinoma associated with hepatocyte steatosis [17]. Castration is a way of studying the consequences of extreme testosterone deficiency in animal models [18]. Castration promotes progression to steatohepatitis through activation of the ER (endoplasmic reticulum) stress pathway and enhancement of macrovesicular droplet.

Some medicinal plants may exert promising pharmacological properties and improve the effectiveness of conventional medications as complementary agents [19]. Vitis vinifera (Grape) are one of the most consumed fruits globally. It possesses a wide range of pharmacological activities due to its rich polyphenol ingredients most of which have been demonstrated to have therapeutic or health promoting properties [20,21], among them, flavonoids are the most abundant and widely studied, recent studies have shown that the beneficial health effects promoted by 
consumption of grape and grape products are attributed to the unique mix of polyphenolic compounds. As the largest group of grape polyphenols, flavonoids are the main candidates considered to have biological properties, including but not limited to antioxidant, anti-inflammatory, anti-cancer antimicrobial, antiviral, cardioprotective, neuroprotective and hepatoprotective [22, 23, and 24]. Therefore, the aim of the present study was to determine the effects of castration, and treatment of castrated subjects by using grape juice on both Ito and Kupffer cells by using Scanning Electron Microscope (SEM)

\section{Materials and Methods}

Swiss albino male mice weighting between (14-17) g., and aged (3weeks) were used in the present study, the mice were obtained from the Animal House, Faculty of Science/ University of Kufa. Animals were kept in ventilated cages, with a temperature of $\left(25 \pm 2 \mathrm{C}^{\circ}\right)$ at $12: 12 \mathrm{~h}$ light, dark cycle was used balanced, rodent food pellet and water were provided ad libitum [25, 26 and 27]. All experimental protocols using live animals were first reviewed, approved and accepted according to guidelines for the care and use of laboratory animals in biomedical research [28, 29 and 30]. A total number of 45 Swiss albino mice were used in the present study. Animals were divided into 5 groups $(\mathrm{N}=15)$, and the treatment was started at the age of 21 days for 6 weeks as:

Group I: Intact male mice received tap-water as control.

Group II: Castrated male mice received tap-water as (positive group).

Group III: Castrated male mice treated daily with $(10 \mu \mathrm{l} / \mathrm{g})$ of grape juice,

The surgical castration method was done according to [31, 32]. Black grape (Vitis vinifera) obtained from local market (Baghdad, Iraq) 100g of grape was blundered by using a commercial blender without separating the seeds, and then it was filtered to remove the residue. The resulting extract $\left(10 \mathrm{mls}\right.$ was stored in the refrigerator at $4^{\circ} \mathrm{C}$, and used after one hour. The extract was prepared according to [33]. A previous study documented that $10 \mu 1 / \mathrm{g} /$ day of grape juice extract was effective dose [34, $35,36]$. For this protocol, we used in the present study $10 \mu \mathrm{l} / \mathrm{g} /$ day and was given daily as orally administered for six weeks.

Animals were sacrificed at the end of the experiments, with using ketamine and xylazine as anesthetic drugs to anesthetize the mice. The preparation procedures for Scanning Electron Microscopy has been described by [33]. Number of both Ito and Kupffer cells in cytoplasmic color in form of brown scale intensity was done according to [37].

\section{Results:}

The present findings of electron micrograph of liver tissue from intact male mice (control) showed a normal structure of both hepatocytes and sinusoids with normal smooth external surface (Figures, 1, 2).

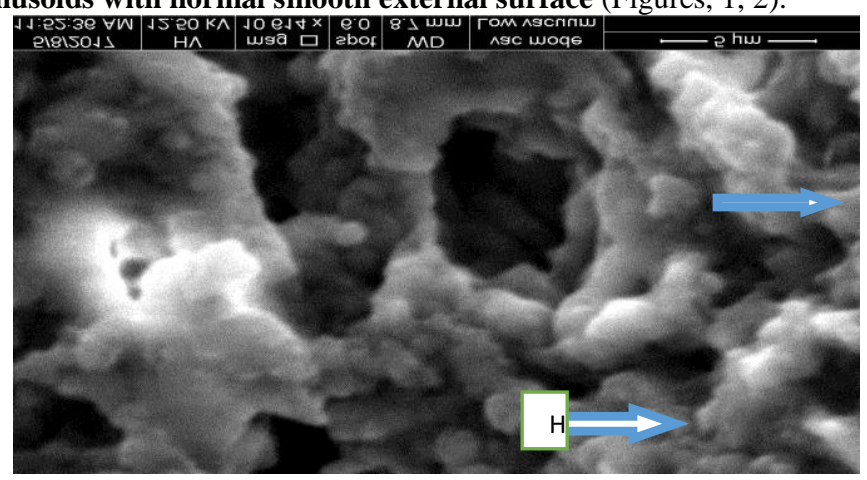

Figure (1): Scanning electron micrographs of liver tissue from intact male mice (control) showing normal structure of both hepatocytes $(\mathrm{H})$ and sinusoids $(\mathrm{S})$.

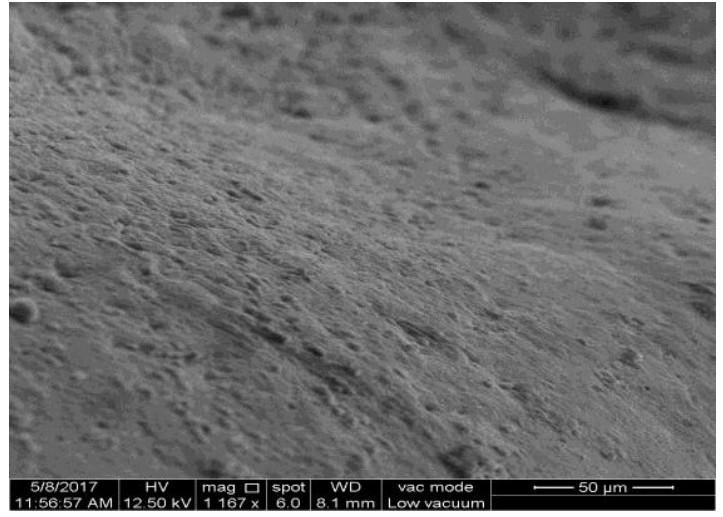

Figure (2): Scanning electron micrographs of liver tissue from intact male mice showing normal smooth external surface.

However the ultrastructure of liver tissue from castrated male mice Showed degeneration processes of hepatocytes with deterioration of sinusoid (Figure 3) as well as aggregation of lipid droplets with rough external surfaces (Figure 4). Moreover, castration was also resulted in aggregations of white blood cells (Figure 5).

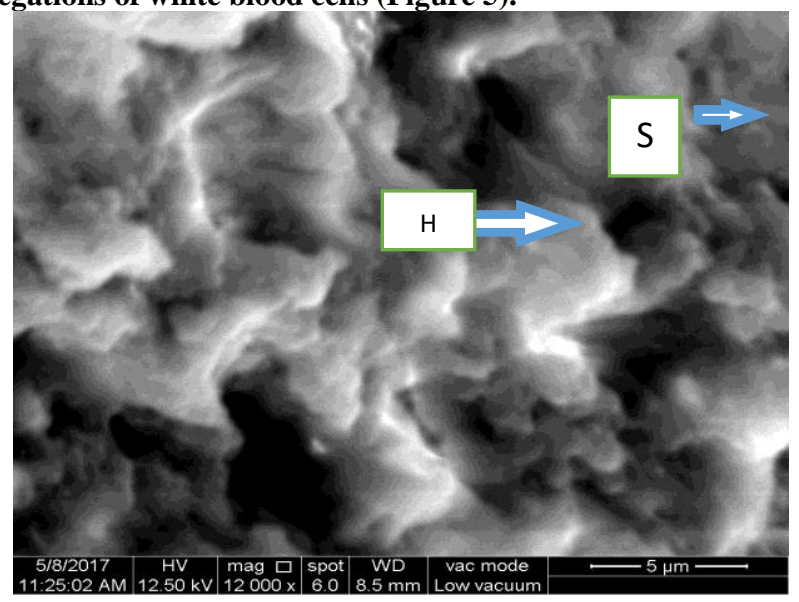

Figure (3): Scanning electron micrograph of liver tissue from castrated group showing degeneration of hepatocytes $(\mathrm{H})$, with distortion of sinusoids (S)

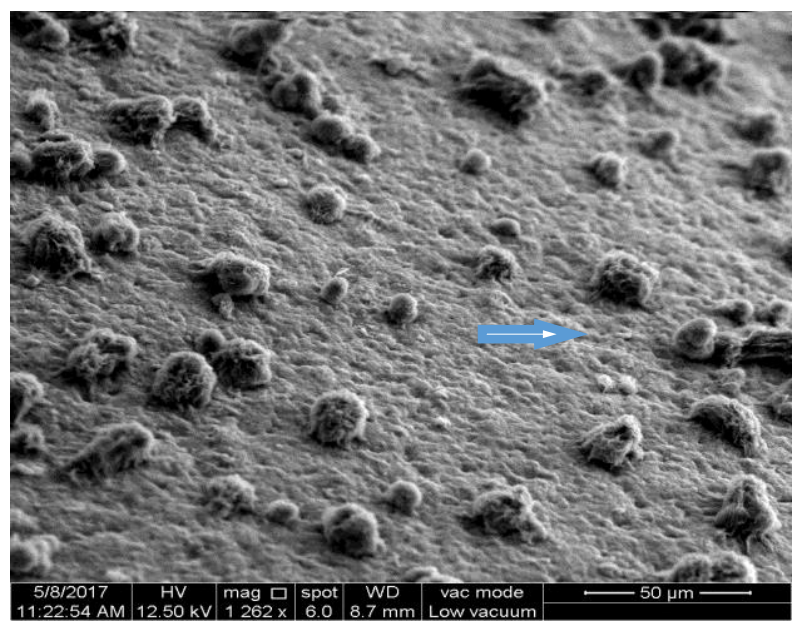

Figure (4): Scanning electron micrograph of liver tissue from castrated group showing aggregation of lipids droplet with rough external surface arrow indicated Lipid droplets 


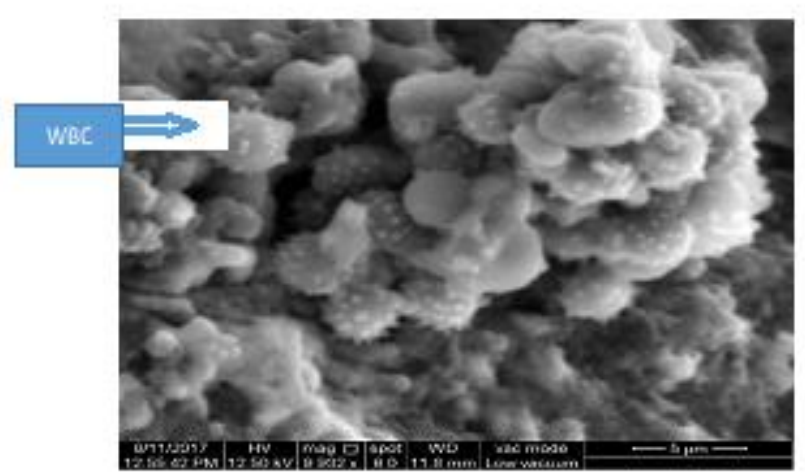

Figure (5): Scanning electron micrograph of liver tissue from castrated group showing an aggregations of white blood cells (WBC) arrow indicated white blood cells

The ultrastructure of liver subject from castrated group treated with $10 \mu \mathrm{l} / \mathrm{g}$ of grape juice (Figure, 6 ) showed regeneration processes in both hepatocytes and sinusoids, with smooth appearance of external surfaces (Figure 7).

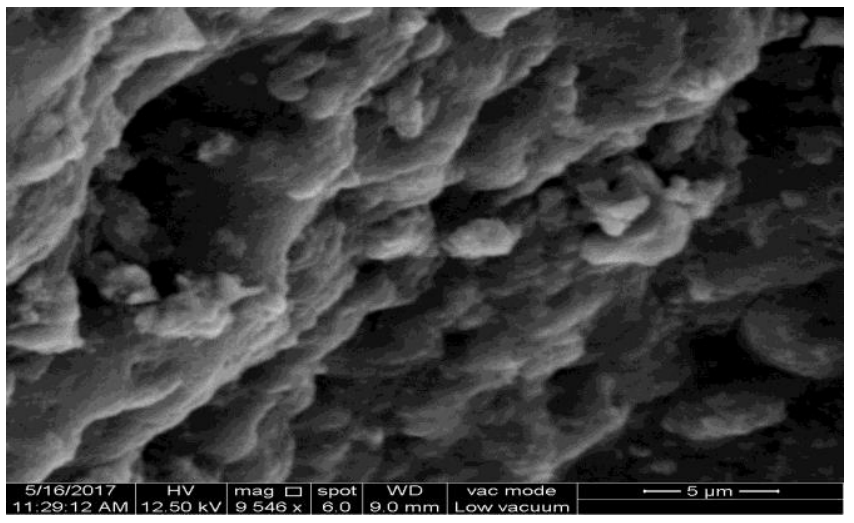

Figure (6): Scanning electron micrograph of liver tissue from castrated group treated with $10 \mu \mathrm{l} / \mathrm{g}$ grape juice showing regeneration of structures in both hepatocytes $(\mathrm{H})$ and sinusoids $(\mathrm{S})$

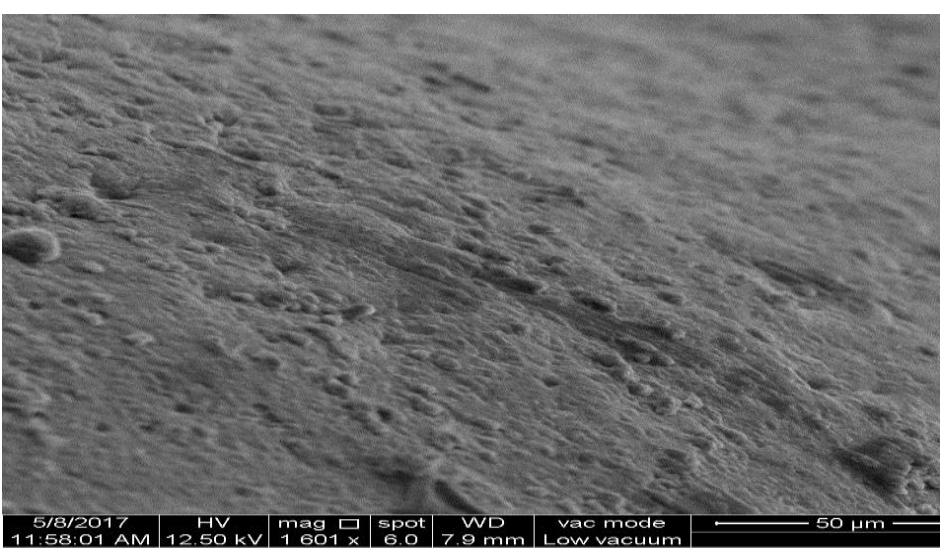

Figure (7): Scanning electron micrograph of liver tissue from castrated group treated with $10 \mu \mathrm{l} / \mathrm{g}$ of grape juice showing normal structure with smooth external surfaces.

\section{Discussion:}

Scanning Electron Microscopical Results: The present results of the electron micrograph of liver tissue from intact (control) group showed a normal structure of hepatic lobules with smooth external surface. Whereas the results of castrated subjects revealed, degeneration processes of hepatocytes and deterioration of sinusoid, with rough external surfaces, as well as aggregations of lipid droplets with concomitant increase in activation of immunity through aggregation of white blood cells. The interpretation of these findings may be attributed to hepatic changes as a results of castration that caused damaged or/may reductions in sinusoidal perfusion arise initially from the effects of hypertrophied hepatic parenchymal cells, swollen with accumulation of lipids within and on their external surfaces. The extension in parenchymal cell plates caused narrowing and distortion the lumen of sinusoids as well as the intrasinusoidal lumen. These results are in agreement with the findings of $[38,39,40]$, who stated that, hepatic steatosis altering the architecture of the sinusoidal network. Studied by [41, 42], demonstrated that the simple steatosis fatty livers may progress to steatohepatitis, and then to fibrosing steatohepatitis with the initiation of capillarization of the sinusoids. The present results are in concomitant with the findings of [43, 44], who concluded that the adhesion of leukocytes to the sinusoidal endothelium is followed by leukocyte infiltration into the hepatic parenchyma to form inflammatory foci. Many studied demonstrated that the deposition of collagen in the space of Diss accentuates the narrowing and distortion of the sinusoidal lumen, further restricting microvascular blood flow [45, 46, and 47]. Electron micrograph of liver tissue from castrated group treated with grape juice showed regeneration processes in both hepatocytes and sinusoids with smooth appearance of external surfaces. Such effects in the present study may be attributed to the protective effects of polyphenolic compounds which have multiple biological effects, including antioxidant, inhibiting lipid peroxidation activity, reduce the lipid load in the liver and reduce the swelling of hepatocytes that resulted in the dilation of spaces between them.

Conclusions: The present study demonstrated that impaired metabolic process related with surgical castration enhanced immune and inflammatory response, represented by activation of Kupffer and Ito cells which lead to hepatic apoptosis and contribute to increase nonalcoholic fatty liver disease. On the other hand the intra gastric application of Grape juice has dramatic effects to restore liver structure in castrated animals.

\section{References:}

1. Wang, H., Thorling, C. A., Liang, X., Bridle, K.R., Grice, J.E., Zhu, Y., Crawford, D. H., Xu, Z. P., Liu, X. and Roberts, M. S., (2015). Diagnostic imaging and therapeutic application of nanoparticles targeting the liver. Journal of Materials Chemistry B, 3(6), pp.939-958.

2. Kaplan, J.B., Kalra, A. and Biggins, S.W., (2017). Liver Anatomy and Function. In Radiation Therapy for Liver Tumors (pp. 3-11). Springer, Cham.

3. Homady MH, ALquraishi LO, Raid D Thanoon and Tanya S Salih (2020): Immunohistohemical and Molecular Studies of Mouse Liver in Castrated Subjects treated with Grape Juice, (2020): American Journal of Clinical Anatomy \& Physiology; Vol., 2 (1): 13-17.

4. Marengo, A., Rosso, C. and Bugianesi, E., (2016). Liver cancer: connections with obesity, fatty liver, and cirrhosis. Annual review of medicine, 67, pp.103-117.

5. Ibrahim, S.H., Hirsova, P. and Gores, G.J., (2018). Nonalcoholic steatohepatitis pathogenesis: sublethal hepatocyte injury as a driver of liver inflammation. Gut, pp.gutjnl-2017.

6. Homady M.H.; AL-quraishi L. O.; Tanya, S. Salih and Juma, A. S. M. (2020) : The Intra Gastric Effects of Grape Juice on 
Histological Structure of Liver Tissue in Castrated Treated Mice. Journal of Human Anatomy. 4(1); 1-6.

7. Merza H. Homady, Hussein Abdul Kadhim, Khalida K. Abbas Al-Kelaby, Dhifaf Zeki Aziz and Naser Jawad Kadhim (2018): Cytotoxic activity of compounded anthracycline against rhabdomyosarcoma canser cell line .. Plant Archives Vol. 18 No. 1: 941-946

8. Luo, W., Xu, Q., Wang, Q., Wu, H., and Hua, J. (2017). Effect of modulation of PPAR- $\gamma$ activity on Kupffer cells M1/M2 polarization in the development of non-alcoholic fatty liver disease. Scientific reports, 7, 44612.

9. Dixon, L. J., Barnes, M., Tang, H., Pritchard, M. T., and Nagy, L. E. (2013). Kupffer cells in the liver. Comprehensive Physiology. 3(2): 785-797.

10. Liqaa O. Ali and Merza H. Homady (2018): Testosterone replacement protects against Non-Alcoholic Fatty Liver Disease in Castrated male mice: Journal of Global Pharma Technology (JGPT), 10(9-10):37-46.

11. Merza H Hamady (2017): The Preputial Gland and its Role in Pheromone Production in Relation to Some Endocrine Factors. Journal of stem Cell Biology and transplantation, 1(1): 4

12. Yin, C., Evason, K. J., Asahina, K., \& Stainier, D. Y. (2013). Hepatic stellate cells in liver development, regeneration, and cancer. The Journal of clinical investigation, 123(5), 1902-1910.

13. Tsuchida, T., and Friedman, S. L. (2017). Mechanisms of hepatic stellate cell activation. Nature Reviews Gastroenterology and Hepatology, 14(7), 397.

14. Saleem, H.;Al-Djaily, A.,N. and Homady,M.H.(2016): Effect of Methanolic Leaf Extract of Moringa oleifera on some Biochemical Markers in obesity induced rats. Reaearch Journal of Pharmaceutical, Biological and Chemical Sciences. Vol. 7, issue 3 .

15. Homady, M.H. and Majeed A. A. (2015): Histochemical and Pheromonal Components of Mouse Preputial Gland in Relation to Estradiol Treatment. European Journal of Scientific Research 129; $179-186$.

16. Senoo, H., Mezaki, Y., and Fujiwara, M. (2017). The stellate cell system (vitamin A-storing cell system). Anatomical science international, 92(4), 387-455.

17. Benten, D., Kluwe, J., Wirth, J. W., Thiele, N. D., Follenzi, A., Bhargava, K. K., and Lutgehetmann, M. (2018). A humanized mouse model of liver fibrosis following expansion of transplanted hepatic stellate cells (p. 1). Nature Publishing Group.

18. Júnior, R. R., Ronconi, K. S., Jesus, I. C. G., Almeida, P. W. M., Forechi, L., Vassallo, D. V. , and Fernandes, A. A. (2018). Testosterone deficiency prevents left ventricular contractility dysfunction after myocardial infarction. Molecular and cellular endocrinology, 460. 14-23.

19. Yuan, H., Ma, Q., Ye, L., and Piao, G. (2016). The traditional medicine and modern medicine from natural products. Molecules, 21(5), 559

20. Homady, M.H. and Majeed A. A. (2017): Pheromonal compounds and Histological Alteration of Castrated Mose Preputial Gland in Relation to Eruca sativa Extract.Biochem. Cell. Arch., 17(2):703-707.

21. Hasona, N.A., Alrashidi, A. A., Aldugieman, T.Z., Alshdokhi, A. M. and Ahmed, M.Q., (2017). Vitis vinifera Extract Ameliorate Hepatic and Renal Dysfunction Induced by Dexamethasone in Albino Rats. Toxics, 5(2), p.11.

22. Homady, M.H. and Majeed A. A. (2017): Histochemical and pheromonal components of mouse preputial gland in relation to F. hormonis treatment. Research J. of Pharmacy and Technology; 10, No. 8: 1-9.
23. Georgiev, V., Ananga, A. and Tsolova, V., (2014). Recent advances and uses of grape flavonoids as nutraceuticals. Nutrients, 6(1), pp.391-415.

24. Cosme, F., Pinto, T., and Vilela, A. (2018). Phenolic Compounds and Antioxidant Activity in Grape Juices: A Chemical and Sensory View. Beverages, 4(1), 22

25. Homady M. H. et al. (2002): Reproductive toxicity and infertility effect of Ferula hormonis Extracts in mice. Theriogenology, 57; 2247-2256.

26. Homady M. H. (2003): Infertility and carcinogenity of Ferula hormonis.A.R.T. And Science, 3, No. 1: 5-8.

27. Martin, D. P. (2010). Guidelines for Animal Care and Use in Biomedical Research. Current Protocols in Pharmacology, 49(1), A-4.

28. Homady M.H. (2002): The influences of some medicinal plant extracts on the aggressivity and fertility of male mice. Philippine J. Science, 130 (3). 119-126.

29. Merza H Hamady (2017): The Preputial Gland and its Role in Pheromone Production in Relation to Some Endocrine Factors. Journal of stem Cell Biology and transplantation, 1(1): 4

30. National Research Council. (2010). Guide for the care and use of laboratory animals. National Academies Press.

31. Khleifat K., Homady M. H. et al. (2002): Histopathological effects of Ferula Hormonis Extract on the colon of male mice. Mu'tah Lil-Buhuth wad-Dirasat (Natural and applied Sciences Series). 17(2); 47-58.

32. Al-Fatlawi, A. A. (2015): Effects of Some Heavy Metals especially $\mathrm{Cr}$ and $\mathrm{Ni}$ on some Histological and Physiological Parameters in male Mice, Ph.D. Thesis, College of Science, Kufa University, Iraq.

33. ALquraishi, L., O. (2018): Immunohistochemical and Ultrastructural studies of liver mice and its relation to endocrine factors. Ph.D. Thesis, College of Science, Kufa University, Iraq.

34. Homady M. H., Hussain H., Tarawneh K., Shakhanbeh J., AlRaheil I. and Brain P.F. (2001): Effects of applications of some medicinal plant extracts used in Jordan on social aggression and gonadal function in male mice. Aggressive Behavior, 27: 221.

35. Homady M.H. (2001): Changes in the testicular and preputial gland structures of mice related to influence of Ferula hormonis extract. The Sciences, 1(3): 108-112.

36. Park, Y. K., Park, E., Kim, J. S., \& Kang, M. H. (2003). Daily grape juice consumption reduces oxidative DNA damage and plasma free radical levels in healthy Koreans. Mutation Research/Fundamental and Molecular Mechanisms of Mutagenesis, 529(1), 77-86.

37. Rodrigues, A. D., Scheffel, T. B., Scola, G., Dos Santos, M. T., Fank, B., de Freitas, S. C. V., and Salvador, M. (2012). Neuroprotective and anticonvulsant effects of organic and conventional purple grape juices on seizures in Wistar rats induced by pentylenetetrazole. Neurochemistry international, 60 (8), 799 - 805.

38. Homady, M.H. and Majeed A. A. (2016): Phermonal components of intact male mice preputial gland in relation to flutamide effects. Jacobs Journal of Anatomy.Vol.3:1-9.

39. Fedchenko, N., and Reifenrath, J. (2014). Different approaches for interpretation and reporting of immunohistochemistry analysis results in the bone tissue-a review. Diagnostic pathology, 9(1), 221.

40. Ohhara, K. (1989). Study of microcirculatory changes in experimental dietary fatty liver. [Hokkaido igaku zasshi] The Hokkaido journal of medical science, 64(2), 177-185.

41. Sabreen Saleem AbdAlkreem Alsaqi , Merza Hamza Homady Almurshidi , Rand Muhammed Abdul-Hussein Al-Husseini1 (2020): Immunohistochemical Correlates of Epidermal Growth 
Factor Receptor Mutations in Lung Adenocarcinoma in Iraq Patient. Indian Journal of Forensic Medicine \& Toxicology, vol., 14, (2): 810-815

42. Aziz, D., Z.; Homady , M. H. and AbdulKadim, H.(2019): Antitumor Activity of Compounded Doxorubicin in RD Cell line by High Content Screening Technique (HCS). Biochem. Cell. Arch. Vol. 18, Supplement 1, pp. 1075-1082, 2018

43. Alkreem Alsaqi, Sabreen Saleem Abd; Al-Husseini, Rand Muhammed Abdul-Hussein; Almurshidi, Merza Hamza Homady (2019): Detection of tumor p53 mutations in lung adenocarcinoma by immunohistochemistry in Iraq patient. Drug Invention Today, Vol 11 (11), 2960-2965.

44. Aziz, D., Z.; Homady , M. H. and Abdul Kadim, H.(2019): Assessment of Compounded Doxorubicin in Cardiac Tissue of Experimental Animals. . Pak.J. Biotechnol. Vol. 14 (4) 811-816.

45. Wafa, H.ALHashemi; Mohummed, E. Mansur and Merza,H. Homady(2019): Intracomparative and Immunocytochemistry study of Parotid, Submandibular and Sublinqual gland in domestic rabbit of Iraq. Biochem. Cell. Arch.19, (2):18 -24.

46. Kadhim, M.M.; Al-Djaily, A.,N. and Homady, M. H. (2019):Assesment of Alpha-Fetoprotein level after treatment with Urtica Dioica phenolic extract in male rat induced by by carbone tetrachloride. Pak.J. Biotechnol. Vol. 14 (4) 811-816.

47. Aziz, D., Z.; Homady, M. H. and AbdulKadim, H.(2019): Antitumor Activity of Compounded Doxorubicin in RD Cell line by High Content Screening Technique (HCS). Biochem. Cell. Arch. Vol. 18, Supplement 1, pp. 1075-1082. 